\title{
Towards a new understanding of migration timing: slower spring than autumn migration in geese reflects different decision rules for stopover use and departure
}

\author{
Andrea Kölzsch, Gerhard J. D. M. Müskens, Helmut Kruckenberg, Peter Glazov, Rolf Weinzierl, \\ Bart A. Nolet and Martin Wikelski
}

A. Kölzsch (akoelzsch@orn.mpg.de), R. Weinzierl and M. Wikelski, Dept of Migration and Immuno-Ecology, Max Planck Inst. for Ornithology, Am Obstberg 1, DE-78315 Radolfzell, Germany. AK and MW also at: Dept of Biology, Univ. of Konstanz, Germany. - H. Kruckenberg, Inst. for Wetlands and Waterfowl Research (IWWR) e.V., Verden (Aller), Germany. - G. J. D. M. Müskens, Alterra Wageningen-UR, Team Animal Ecology, Ecotoxicology and Wildlife Management, Wageningen, the Netherlands. - P. Glazov, Inst. of Geography, Russian Academy of Sciences, Moscow, Russia. - B. A. Nolet, Dept of Animal Ecology, Netherlands Inst. of Ecology (NIOO-KNAW), Wageningen, the Netherlands, and: Computational Geo-Ecology, Dept of Science, Inst. for Biodiversity and Ecosystem Dynamics, Univ. of Amsterdam, the Netherlands.

\begin{abstract}
According to migration theory and several empirical studies, long-distance migrants are more time-limited during spring migration and should therefore migrate faster in spring than in autumn. Competition for the best breeding sites is supposed to be the main driver, but timing of migration is often also influenced by environmental factors such as food availability and wind conditions.

Using GPS tags, we tracked 65 greater white-fronted geese Anser albifrons migrating between western Europe and the Russian Arctic during spring and autumn migration over six different years. Contrary to theory, our birds took considerably longer for spring migration ( 83 days) than autumn migration ( 42 days). This difference in duration was mainly determined by time spent at stopovers.

Timing and space use during migration suggest that the birds were using different strategies in the two seasons: In spring they spread out in a wide front to acquire extra energy stores in many successive stopover sites (to fuel capital breeding), which is in accordance with previous results that white-fronted geese follow the green wave of spring growth. In autumn they filled up their stores close to the breeding grounds and waited for supportive wind conditions to quickly move to their wintering grounds. Selection for supportive winds was stronger in autumn, when general wind conditions were less favourable than in spring, leading to similar flight speeds in the two seasons. In combination with less stopover time in autumn this led to faster autumn than spring migration.

White-fronted geese thus differ from theory that spring migration is faster than autumn migration. We expect our findings of different decision rules between the two migratory seasons to apply more generally, in particular in large birds in which capital breeding is common, and in birds that meet other environmental conditions along their migration route in autumn than in spring.
\end{abstract}

Migration timing theory suggests that animals should adopt time minimisation during spring migration in order to arrive early at their breeding grounds (Kokko 1999). Thus, they can profit from a long breeding season and compete for highly suitable nesting sites (Moore et al. 2005). During autumn migration animals are not driven by such time pressure, leading to the general expectation that migration speed is lower in autumn than in spring (Nilsson et al. 2013), because slow migration is expected to be energetically cheaper or less risky. This difference in timing might be caused by higher movement speeds or shorter stopover periods along the route.

Large flying migrants that use energy-powered flapping flight have a small window of possible air speeds (Alerstam et al. 2007, Pennycuick et al. 2013). They also have an upper speed limit as energy requirements raise greatly above a certain flight speed. Higher speeds have been observed in many bird species that take advantage of favourable winds during migration flight, increasing ground speeds up to double their maximum air speed (Liechti 2006, Alerstam et al. 2007, Safi et al. 2013). This use of favourable winds as well as avoidance of adverse winds is an important strategy for migrants to minimise energy expenditure during migration. Also for animals that use soaring flight this phenomenon has been explored in great detail; they are able to save even more energy during flight than birds bound to use flapping flight (Liminana et al. 2013, Shamoun-Baranes et al. 2003).

Most migrants do not move non-stop between their wintering and breeding grounds, but use several stopover sites for resting and refuelling on their way (Hedenström 
and Alerstam 1997). Especially for flying migrants using flapping flight, such periods are essential during migration (Drent et al. 2007). Stopover duration, usually representative of the amount of energy gain, has been suggested generally more important than flight speed for the difference of timing of spring and autumn migration (Nilsson et al. 2013). For many species, foraging conditions are better in spring than in autumn, which allows shorter stopovers with higher foraging gain, leading to shorter migration duration (Shamoun-Baranes et al. 2003). However, migration routes often span several thousands of kilometres, and foraging and weather conditions might vary in a complex manner.

Large waterbirds that are breeding in the northern Arctic experience such environmental complexity along their routes. During summer, conditions in the breeding grounds are highly suitable, but summers in the Arctic are very short (Prop et al. 2003) and birds seem to be driven south early by the first snow and ice events. Bewick's swans Cygnus columbianus bewickii, for example, migrated ahead of the ice front in autumn to avoid being trapped by early ice events (Nuijten et al. 2014). In spring, on the other hand, they followed the stepwise retreating ice front very closely, being delayed in their migration by food availability in successive sites. This delay enabled them to acquire additional energy stores from highly nutrient rich early shoots to bring to their breeding grounds, consistent with their capital breeding strategy (Drent and Daan 1980, Drent et al. 2006, Nolet 2006). Consequently, the migration duration of Bewick's swans appears longer in spring that in autumn, but this has not yet been shown repeatedly on the individual level.

Spring migration being driven by environmental conditions has also been observed in greater white-fronted geese Anser albifrons. They were shown to follow the green wave of spring growth and spend long times at stopovers for refuelling (van der Graaf et al. 2006, van Wijk et al. 2012). Also white-fronted geese are partly capital breeders that build up energy stores before and during migration for use at the breeding grounds (Spaans et al. 1999). This strategy allows them to directly commence breeding and make optimal use of the short but prolific Arctic summer for their offspring (Drent et al. 2007). Furthermore, their slow, stepwise migration enables the geese to subsequently predict weather conditions (Tombre et al. 2008, Kölzsch et al. 2015) and thus not arrive at their breeding grounds if snow still covers most breeding and foraging sites, which might happen to other mainly non-stop migrants (Green et al. 2002, Clausen and Clausen 2013). The requirements of extra feeding and to predict conditions ahead in space and time theoretically do not apply during autumn migration, and it might therefore be expected that autumn migration is shorter than spring migration also in this species.

In order to explore their migration strategies and evaluate this hypothesis, we have tracked a large number of greater white-fronted geese with GPS transmitters during spring as well as autumn migration. We show that migration duration was indeed longer in spring than in autumn. Consequently, we examined whether this difference was caused by lower flight speeds, larger distance travelled or longer stopover duration in spring than autumn migration. Furthermore, we tested the hypothesis that different environmental decision rules governed migration synchrony and timing decisions, namely the availability of high quality food in spring (green wave and capital breeding) and the selection of favourable wind conditions in autumn. A complex picture of interdependencies of wind conditions and stopover usage appeared, revealing how white-fronted geese tuned space-use and timing of their seasonal migrations.

\section{Methods}

\section{GPS tracking}

Individual white-fronted geese were caught between November and January in their wintering grounds in the Netherlands (with help of the Dutch Goose Catcher Association; 2006, 2007, 2008, 2013, 2014) and in early August, during postbreeding moult, on Kolguev Island, Russia (2013). In 2006 2008 adult males were equipped with backpack solar GPS/ PTT transmitters (Microwave, $45 \mathrm{~g}$ ); in 2013 and 2014 geese were caught in family groups and equipped with backpack solar GPS/GSM transmitters (E-obs, $45 \mathrm{~g}$ ) or neckbandattached solar GPS loggers (Univ. of Konstanz, $35 \mathrm{~g}$ ). It is known that both types of tags have a short-term habituation effect on goose behaviour (Ely 1990, Demers et al. 2003), reproduction and body condition (Glahder et al. 1998, Menu et al. 2000, Clausen and Madsen 2014), but no long-term effect. As we have tagged the geese 4-10 weeks before migration commencement, we thus do not expect any influence of tag-induced effects on our data sets. As white-fronted geese migrate together in family groups (within larger groups), no sex or age effect is expected due to the inclusion of tracks of males, females and juvenile birds. After catching, families of birds have been observed together, so their bonds are usually not affected by capture and marking. Per family group, we used here only one track, namely the one with most GPS positions. The number of GPS positions collected per day ranged from 2 to 96, depending on tag capacity and solar conditions.

In total, we obtained data of 49 autumn migration tracks (2006: $\mathrm{n}=1,2007: \mathrm{n}=6,2008: \mathrm{n}=1,2009: \mathrm{n}=3,2013$ : $\mathrm{n}=23,2014: \mathrm{n}=15 ; 38$ adult males, 7 adult females, 2 juvenile males, 2 juvenile females) and 53 spring migration tracks (2006: $\mathrm{n}=3,2007: \mathrm{n}=12,2008: \mathrm{n}=5,2009: \mathrm{n}=4$, 2014: $\mathrm{n}=29$; 42 adult males, 6 adult females, 2 juvenile males, 3 juvenile females). Some individuals were tracked for more than one year; for independence, only one spring and autumn migration track was selected per individual (Fig. 1). We used both one spring and autumn migration for 37 individuals, but they were not necessarily successive in time. For 2006-2009 we selected the first year's track for each individual, as tag performance deteriorated with time. The quality of tags used in 2013-2014 was better, so for each individual we selected the year that the GPS track had most data points.

Spring migration tracks were compiled as the GPS positions starting from the last position in the wintering grounds (mainly the Netherlands) until arrival to the breeding grounds; autumn migration tracks started from the last position in their moulting sites (for breeding birds overlapping with the breeding site) until arrival to the general wintering area (northern Germany or the Netherlands). Moulting and 

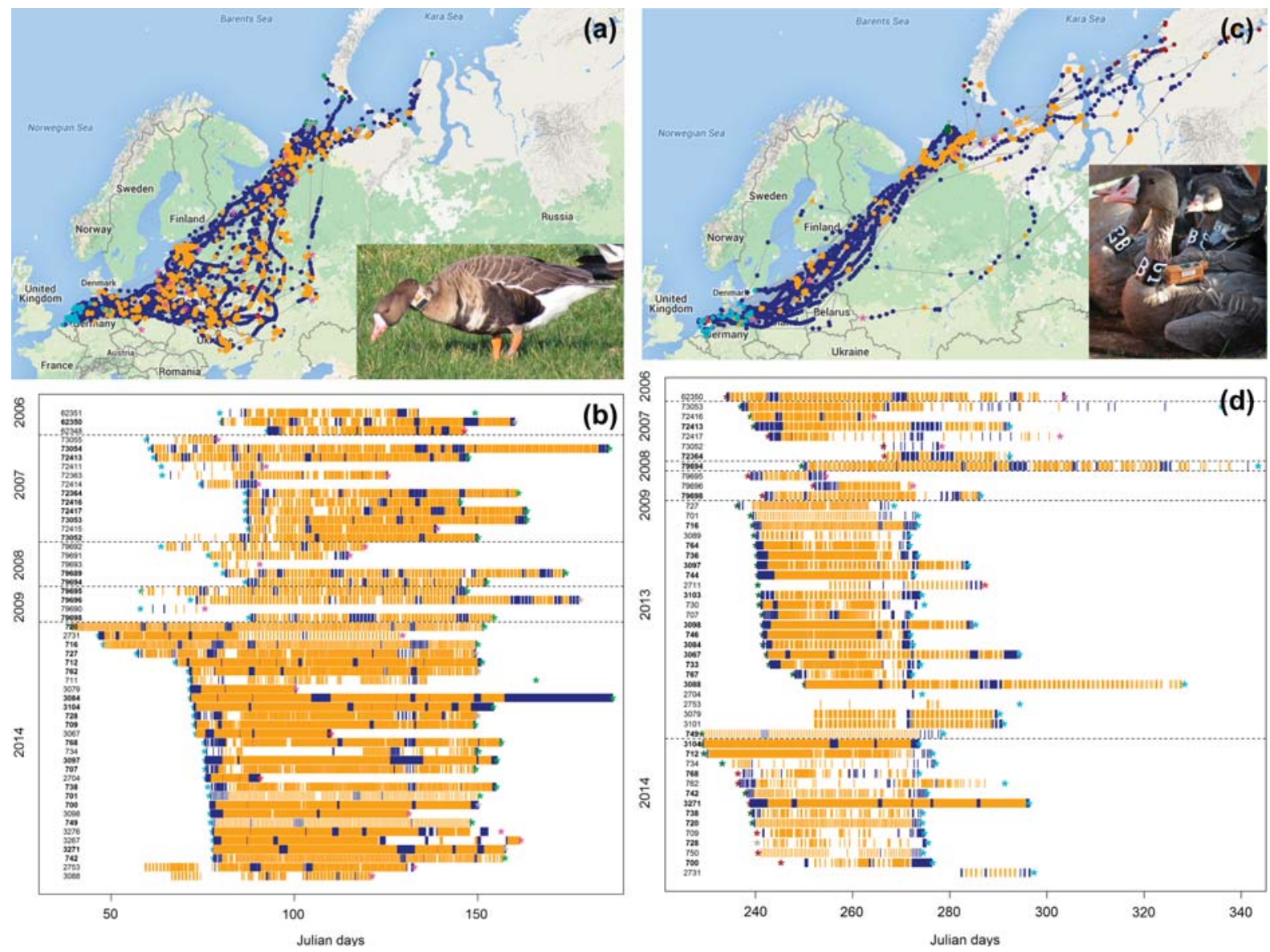

Figure 1. Migration tracks and timelines of individual white-fronted geese, tracked in 2006-2014. (a) GPS positions and (b) timelines of 53 different geese during spring migration. (c) GPS positions and (d) timelines of 49 different geese during autumn migration. Dark blue colour indicates positions in flight, orange stopover. Light blue stars show the start of wintering, dark red the end of moulting and green the arrival at/departure from breeding sites. Pink stars mark positions where the tracks stopped for unknown reasons before migration was finalised, black stars show positions where geese have been shot. In the timelines, IDs of individuals that were selected for detailed analyses (see text) are highlighted in bold ( $\mathrm{n}=31$ in spring, $\mathrm{n}=27$ in autumn). Insets: white-fronted geese with (a) neckband GPS logger and (c) backpack GPS/GSM transmitter. Photography by A. Kölzsch.

breeding sites were determined from stationary periods of GPS positions (De Boer et al. 2014).

\section{Data deposition}

The GPS migration tracks are uploaded to Movebank (<www.movebank.org >), available in the study "Migration timing in white-fronted geese", and published in the MovebankData Repository-DOI: 10.5441/001/1.31c2v92f (Kölzsch et al. 2016).

\section{Data processing}

During spring as well as autumn migration white-fronted geese used a number of stopover sites. These were manually extracted from the data sets as sites where a bird did not displace further than $30 \mathrm{~km}$ for at least $48 \mathrm{~h}$, allowing for maximally one detour (van Wijk et al. 2012). Stopover site locations were then determined as the centre of all GPS positions assigned to it, the average of longitudes and latitudes. For each stopover site we determined duration of stay and distance and direction to the following stopover or wintering/breeding site. Migration duration was calculated as the time the goose took to travel (and stop) between the breeding/moulting and first wintering site (autumn migration) or between the last wintering and the breeding/prospecting (if a bird was a non-breeder) site (spring migration). This differs from the general definition of migration duration, which would also include the time of fuelling for migration at the breeding/moulting or last wintering site, respectively. However, our data did not allow determining the time of switch from wintering/moulting to migration fuelling.

For subsequent analyses, we selected complete migration tracks; at stopovers we allowed for gaps of 1-5 days, between stopovers (during migration flight) only data with gaps of $<1$ day were included. Tracks that were incomplete due to signal loss or the bird being shot before arrival to the wintering or breeding grounds, respectively, were taken out. The resulting data set (selected tracks indicated by bold ID in Fig. 1) comprised 63973 GPS positions (including altitude, instantaneous speed and heading) of 27 complete autumn migration tracks (2007: $\mathrm{n}=2,2008: \mathrm{n}=1,2009: \mathrm{n}=1,2013: \mathrm{n}=13$, 2014: $\mathrm{n}=10$; 20 adult males, 6 adult females and 1 juvenile male) and 31 complete spring migration tracks (2006: $\mathrm{n}=1,2007: \mathrm{n}=7,2008: \mathrm{n}=2,2009: \mathrm{n}=3,2014: \mathrm{n}=18$; 
25 adult males, 2 adult females and 2 juvenile males and 2 juvenile females; Fig. 1), and it allowed accurate analyses of migration timing.

\section{Stopover and migration routes}

We compared spring and autumn migration first by simple measures as migration duration, migration speed (Nilsson et al. 2013), distance travelled, arrival at and departure from the breeding/moulting sites, number of stopovers, stopover duration and distance between stopovers. The influence of season on those variables was tested by comparing generalized linear mixed models (GLMMs, R package 'lme4') with and without the relevant fixed factor(s) with year and individual bird as random factors (same random factors for all subsequent GLMMs) by a likelihood ratio test (LRT).

Further, space use and timing of autumn and spring migration was contrasted by overlapping the migration tracks with ten arbitrary, equally spaced crossing lines along their route. As a line of reference, we have determined the great circle line (orthodrome, using the Vincenty formulae) between northern Friesland (Netherlands, wintering site, crossing 1) and Kolguev Island (Russia, breeding site, crossing 10). Between these two lines, eight additional, equidistant crossings were selected (Fig. 2). For each of the ten crossings, we have drawn a perpendicular line on the map and calculated the position at which each goose migration track crossed the ten crossing lines. Times of crossing and distance of the crossing points to the great circle line then indicated timing of migration and how far southeast the respective goose was travelling. To evaluate how similar the migration tracks of both seasons were within the years (i.e. how much they were driven by environmental factors) as opposed to between the years, we calculated for each crossing line the similarity $s$, i.e. the intra-year correlation coefficient (R-package 'rptR'), for timing and distance to the great circle line with year as the grouping factor.

\section{Wind support}

For further comparison of stopover behaviour during spring and autumn migration we examined wind support. As white-fronted geese have been shown to use wind support (= tail wind), but not to compensate for cross winds (Safi et al. 2013), we chose to only consider wind support here. Wind conditions were obtained 1) for each of the ten line crossings and 2) for each stopover site by track annotation (Dodge et al. 2013; Env-DATA tool by Movebank) using surface-level winds (10 $\mathrm{m}$ above the ground) at a resolution of $6 \mathrm{~h}$ and $0.75^{\circ}$ (ECMWF ERA-interim weather model). For the line crossings we determined wind support at time of crossing and included the results in the above similarity analysis. For the stopover sites we obtained wind conditions for all $6 \mathrm{~h}$ intervals starting two weeks before stopover arrival up to two weeks after stopover departure and calculated the wind support that the bird had/would experience(d) then.

For proper evaluation of the hypothesis that the geese select for favourable winds at departure, for each stopover, we calculated wind support at observed departure and if each bird would have departed 2 up to 10 days earlier (or less when the total stopover duration was shorter; see example in
Supplementary material Appendix 1 Fig. A1). The two days minimum shift was chosen to avoid temporal correlation of wind conditions, which had been estimated from our complete data set (significant autocorrelation coefficients $>0.2$ for all time lags $<48 \mathrm{~h}$ ). The dynamics of wind support differences between the observed and the early departures were analysed and compared between spring and autumn using LRTs of GLMMs with year and individual bird as random factors.

To examine if the geese also experienced more favourable wind conditions during actual migration flight (after having departed from the stopovers), we analysed GPS flight positions between stopovers. Flight positions were selected by GPS instantaneous ground speed being above $10 \mathrm{~m} \mathrm{~s}^{-1}$ (a threshold that lay at the minimum between two peaks of the bimodally distributed GPS speeds of all positions outside of stopovers) and below $45 \mathrm{~m} \mathrm{~s}^{-1}$ (the maximum GPS speed of the better quality GPS/GSM transmitters). From all determined flight positions we calculated height above ground, using GPS altitudes and elevations from the ASTER digital elevation model V002. This height and the instantaneous GPS ground speeds were compared between autumn and spring migration using LRTs of GLMMs with year and individual bird as random factors.

Because of sample size limitations and because the effect of departure wind selection was expected strongest during the first day after departure, we only included flight positions for the first day after stopover departure for the wind support analysis. We used surface level winds (ECMWF, see above) to calculate wind support for each selected GPS flight position at the time when the goose was observed there and 2 up to 10 days before, i.e. if it had left the previous stopover earlier. Using an LRT of GLMMs, wind support dynamics were evaluated and compared between spring and autumn.

As wind conditions are known to differ by height and goose flight heights were often much above the ground layer, we additionally annotated our data set with pressure level winds at the respective altitudes (ECMWF ERA-interim weather model). This led to a significantly reduced sample size, as those values were not available for many positions. Because the analysis outcomes using surface-level winds and pressure level winds did not differ, we only show results for the former.

\section{Results}

\section{GPS tracking}

The obtained spring migration routes (Fig. 1a) show that our successfully tracked white-fronted geese $(n=31)$ winter mainly in the Netherlands and northern Germany, from where they travel in a wide front to their about 2800-3600 $\mathrm{km}$ distant breeding grounds on Kolguev Island $(\mathrm{n}=21)$, Nenetsky Okrug $(\mathrm{n}=3)$, Novaya Zemlya $(\mathrm{n}=3)$ and Yamal Peninsular $(n=4)$. Five of the total 31 birds were lost or shot (see below) before we could obtain their breeding status. Of the remaining 26 individuals, all non-breeders $(n=7)$ were found to stay in breeding sites in early summer for at least one week, possibly exploring the sites for breeding attempts in later years (prospecting). Successful breeders $(n=10)$ stayed 

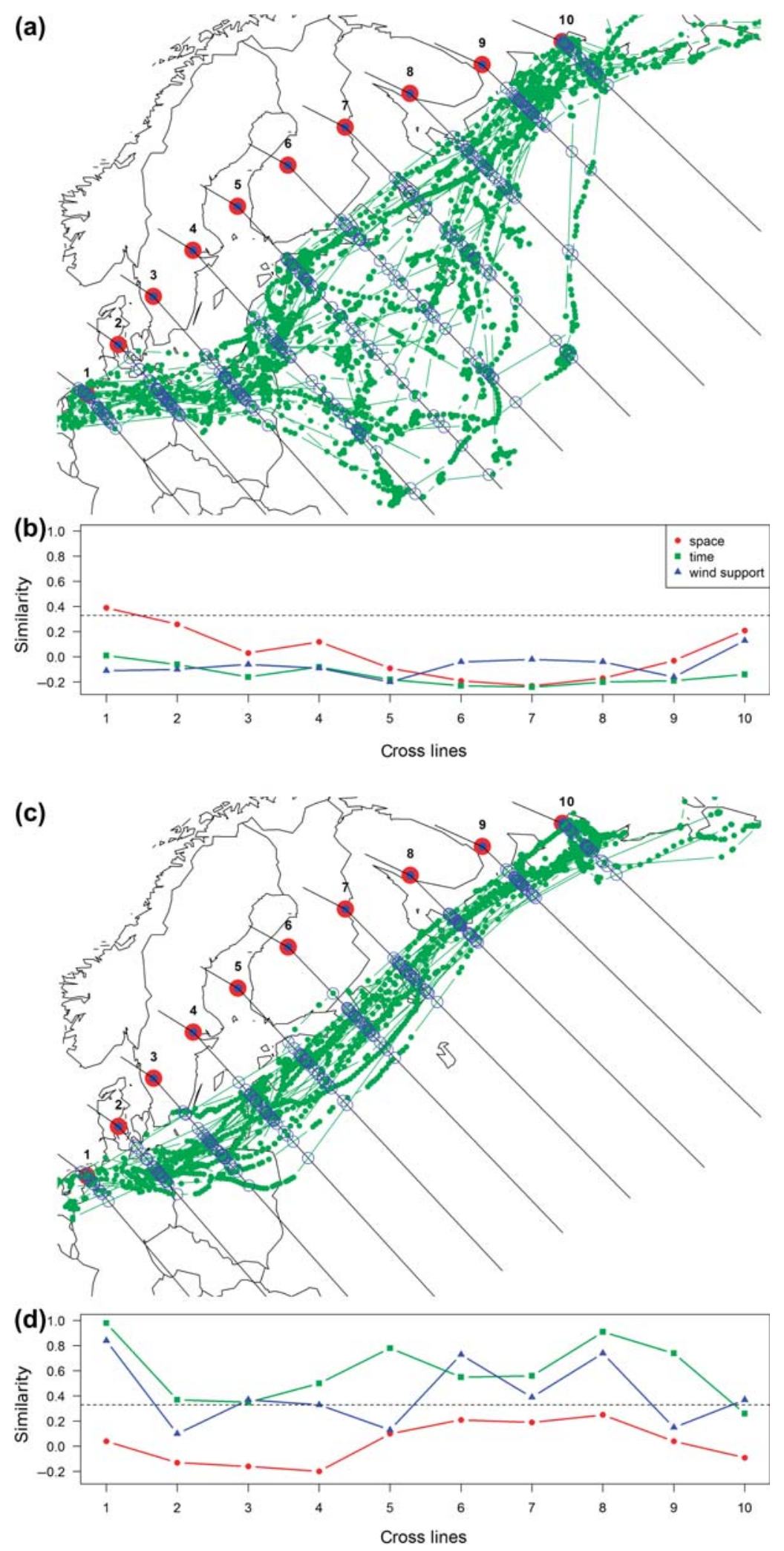

Figure 2. Similarity, $s$ of migration space use, timing and wind support during autumn and spring migration at regularly spaced 'crossing lines'. Crossing lines are numbered 1,2, . 10 along the great circle line between a central wintering area (Friesland, 1) and the main breeding site (Kolguev, 10). (a) Map of spring migration tracks (green), the crossing lines and intersections between them (blue circles). (b) Within-year similarity values of space use (red), time (green) and wind support (blue) when the geese pass each crossing line during spring migration. (c) Map of autumn migration (like a). (d) Similarity values during autumn migration (like b). The within year similarity values indicate the effect of environmental drivers on the space (great circle distance to northern great circle line) and time that the geese crossed the ten crossing lines. The horizontal, dotted lines in (b) and (d) indicate significant similarity values $(s \geq 0.33)$. The agreement of similarity of time and wind support indicates that the geese follow favourable wind conditions instead of a constant migration schedule. 
all summer with their chicks in the breeding site, moulted there and returned in a rather straight line to the wintering grounds. Geese with failed broods $(\mathrm{n}=9)$ continued $800-$ $1500 \mathrm{~km}$ east in July, joining non-breeders at moulting sites on Taimyr Peninsular $(n=10)$, Novaya Zemlya $(n=2)$ or Gydan Peninsular $(n=2)$. Two non-breeders (both juvenile females) stayed on Kolguyev Island until moult, possibly assisting their parents in a new brood (Barry 1967, Ely 1976, Fox et al. 1995). In late summer, the non-breeders and failed breeders started autumn migration (Fig. 1c) from their moulting sites and moved along the coast lines to the wintering grounds (two outliers joined the southern route of the Hungarian population of white-fronted geese), sometimes somewhat later than the successful breeders.

Several of our tracked geese were shot by human hunters or the signal was lost due to unknown causes (tag failure, shot, predation; Fig. 1). Of the confirmed shot birds $(n=5)$, three were killed during the Russian spring hunt and two were shot by derogation upon arrival in the Netherlands. The number of lost birds was very high $(\mathrm{n}=22)$ and times often coincided with hunting season, indicating that most of them were also shot. During spring, two geese were lost in Poland, three in the Baltic States, two in Belarus and nine in Russia. In autumn, we lost four birds in Russia, one in the Baltic States and one in northern Germany. For the following analyses on migration space use and timing, all of the incomplete migration tracks were disregarded.

\section{Stopovers and migration routes}

From the maps and migration timelines (Fig. 1) it becomes obvious that the migration routes and timing differed greatly between spring and autumn. Migration duration, one of the most widely used measures to compare spring and autumn migration, was significantly different in our two data sets (LRT, $\chi^{2}=53.07, \mathrm{DF}=1, \mathrm{p}<0.001$ ): The geese migrated on average 83 days in spring and took only about 42 days during autumn migration (Fig. 3a). While they travelled larger distances during spring migration than in autumn (ca $3900 \mathrm{~km}$ in spring versus $3300 \mathrm{~km}$ in autumn, Fig. 3c; LRT, $\left.\chi^{2}=11.09, \mathrm{DF}=1, \mathrm{p}<0.001\right)$, migration duration was not related to distance travelled, but significantly related to the number of stopovers (LRT, $\chi^{2}=35.37, \mathrm{DF}=1, \mathrm{p}<0.001$ ) and the cumulative duration of stopovers along the route (LRT, $\chi^{2}=97.46, \mathrm{DF}=1, \mathrm{p}<0.001$; Fig. $3 \mathrm{~b}$ ). The differences in migration duration clearly governed migration speeds (spring: $47.5 \mathrm{~km} \mathrm{day}^{-1}$, autumn: $86.5 \mathrm{~km}$ day $^{-1}$ ), and the log-quotient of the two (Nilsson et al. 2013) $Q=-0.302$ indicates that spring migration was slower.

Departure and arrival times related to migration duration if considering spring and autumn migration separately (Fig. 3d). Autumn migration duration was not affected by departure date, but was significantly longer for birds that arrived later in the wintering grounds (LRT, $\chi^{2}=47.56, \mathrm{DF}=1$, $\mathrm{p}<0.001)$, possibly having been delayed by travel with juveniles. The duration of spring migration was significantly related to departure (LRT, $\left.\chi^{2}=20.38, \mathrm{DF}=1, \mathrm{p}<0.001\right)$ as well as arrival time (LRT, $\chi^{2}=214.15, \mathrm{DF}=1, \mathrm{p}<0.001$ ), birds that departed early also arrived late.

The relationships between shortest distance between breeding/moulting and wintering sites and distance actually travelled differed between the seasons (standardised major axis estimation (SMA), interaction between season and shortest migration distance, LRT, $\chi^{2}=11.53, \mathrm{DF}=1$, $\mathrm{p}<0.001$; Fig. 3e); many of our geese took long detours in spring, whereas they kept relatively close to the shortest route in autumn. One indication that this difference in travel routes was due to food availability is the difference in relation between average stopover duration and distance to the next stopover site (SMA, interaction between season and stopover duration, LRT, $\chi^{2}=28.56, \mathrm{DF}=1, \mathrm{p}<0.001$; Fig. 3f). The shallower slope for spring migration indicates that they stayed (and fed) relatively longer at stopovers before continuing, most likely being delayed by climatic conditions and acquiring extra energy stores (capital breeding). Distances between subsequent stopovers were also smaller in spring (ca $480 \mathrm{~km}$ ) than in autumn (ca $1280 \mathrm{~km}$ ) (LRT, $\left.\chi^{2}=43.89, \mathrm{DF}=1, \mathrm{p}<0.001\right)$.

Within-year similarity $s$ of space use, timing and selection of wind support during the two migrations revealed that our geese were not synchronised in time, space or by wind conditions during spring migration (Fig. 2a-b). The only slight indication of synchronisation within the year during spring was place of departure from the wintering grounds (crossing $1, s=0.39$ ). In autumn, within-year space use showed no signs of synchronisation, but timing was highly similar for all sites along the route $(0.33<s<0.98)$ except departure from Nenetsky Okrug (crossing 10, $=0.26$ ), indicating that there might be a common environmental factor that drove autumn migration timing of our population of white-fronted geese. This factor might have been wind conditions, as was supported by the high similarity of wind support in autumn for most of the line crossings $(0.33<s<0.84$, Fig. $2 c-d)$. Exceptions were the crossings 2,5 and $9(0.1<s<0.15)$, which were close to typical autumn stopover sites (crossings 5 and 9) or first wintering sites (crossing 2, Fig. 1).

\section{Wind support}

Individual wind support at true departure from stopover sites did not differ between the seasons (LRT, $\chi^{2}=0.78, \mathrm{DF}=1$, $\mathrm{p}=0.38)$. However, wind support dynamics along the different days of shifted departure differed significantly by season (LRT, $\chi^{2}=41.11, \mathrm{DF}=1, \mathrm{p}<0.001$ ), i.e. the average wind support of up to 10 days before observed departure was lower in autumn than in spring (Fig. 4). Furthermore, within the wind support patterns of autumn only, there was a significant effect of shifted days if selecting only values with shifts $\leq 6$ days (LRT, $\chi^{2}=19.32, D F=1, p<0.001$, Fig. 4b). Thus, in autumn, wind support at observed departure was higher than wind support if the geese would have left 2-6 days earlier.

Between subsequent stopover sites, the birds were travelling on average 1.7 days in spring and 2.3 days in autumn (LRT, $\chi^{2}=6.25, \mathrm{DF}=1, \mathrm{p}=0.01$ ), which is closely related to the different distances between stopovers in the seasons. Consequently, the average speed of travel between stopovers as well as the total number of travel days during the complete migrations did not differ (spring: $5.7 \mathrm{~m} \mathrm{~s}^{-1}, 23.6$ days; autumn: $5.5 \mathrm{~m} \mathrm{~s}^{-1}, 26.6$ days).

Of all GPS positions between stopovers, 34.1\% and $30.1 \%$ were true flight positions in spring and autumn, 

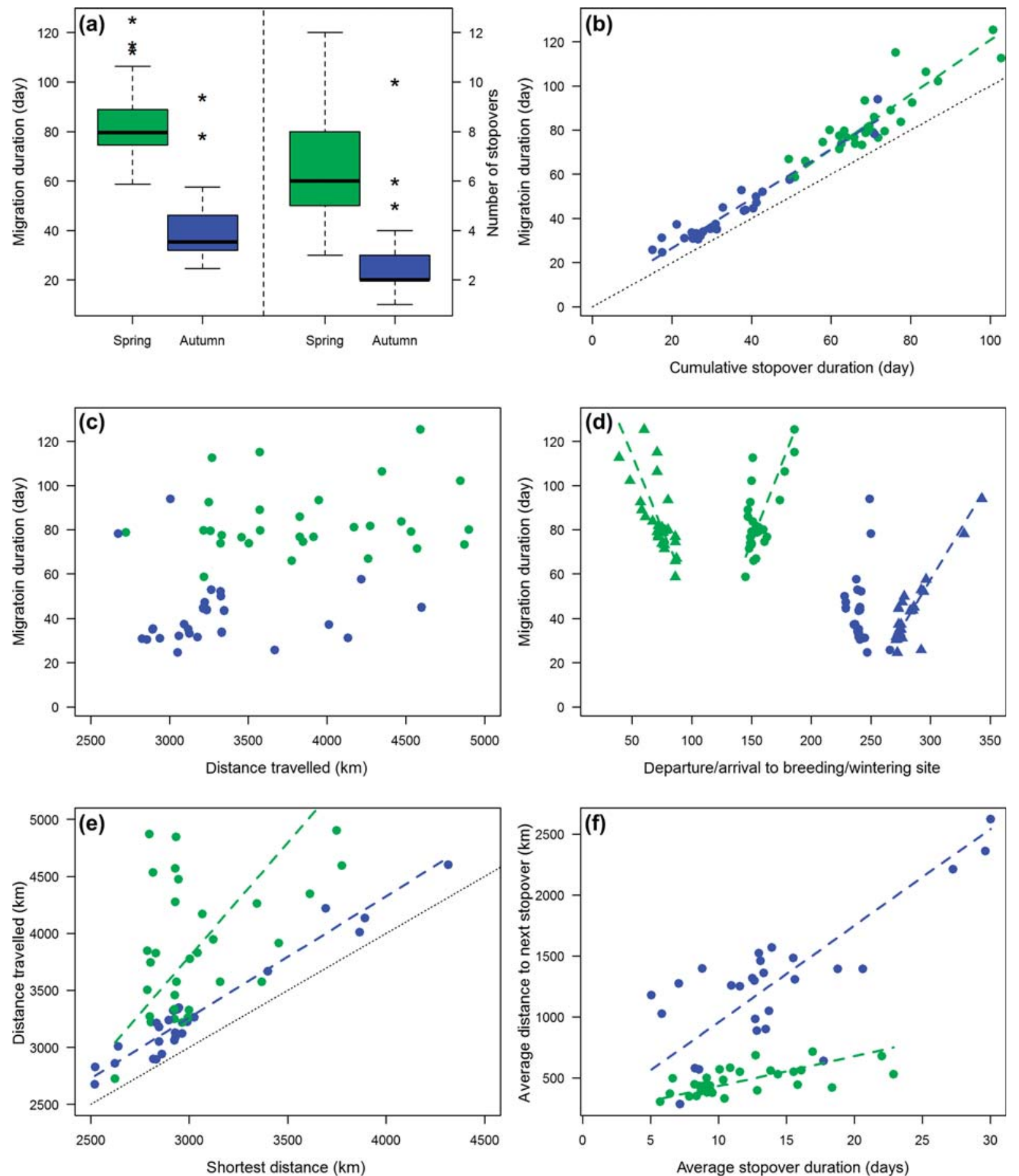

Figure 3. Properties of goose stopover behaviour during spring (green) and autumn (blue) migration. (a) Boxplots of migration duration and number of stopovers between the two seasons. (b) Cumulative time (days) that migrating geese spent at stopovers in relation to total migration duration (days). (c) Distance $(\mathrm{km})$ that the geese travelled (cumulative distance between consecutive stopovers) versus migration duration (days). (d) Individual arrival and departure time to/from wintering (triangles) and breeding/moulting sites (circles; Julian days) versus migration duration (days). (e) Shortest distance between wintering and breeding/moulting sites versus travelled distance (km; see c). (f) Individual average stopover duration versus average distance travelled to the subsequent stopover site, indicating general fuelling relations. Dashed lines indicate significant SMA linear relationships (conform to GLMM results). Where appropriate, black dotted lines show lines of $y=x$.

respectively. Heights above ground of those positions differed between seasons (LRT, $\chi^{2}=57.49, \mathrm{DF}=1, \mathrm{p}<0.001$ ) and were on average $165 \mathrm{~m}$ (max. $1237 \mathrm{~m}$ ) in spring and $323 \mathrm{~m}$ (max. $2768 \mathrm{~m}$ ) in autumn (Fig. 5a). Instantaneous flight ground speeds were similar between spring (ca 19.0 $\mathrm{m} \mathrm{s}^{-1}$ ) and autumn (ca $19.8 \mathrm{~m} \mathrm{~s}^{-1}$; LRT, $\chi^{2}=1.41$, DF $=1$, $\mathrm{p}=0.24$; Fig. $5 \mathrm{~b}$ ), indicating that experienced wind support was similar. This was likely achieved by selection for 

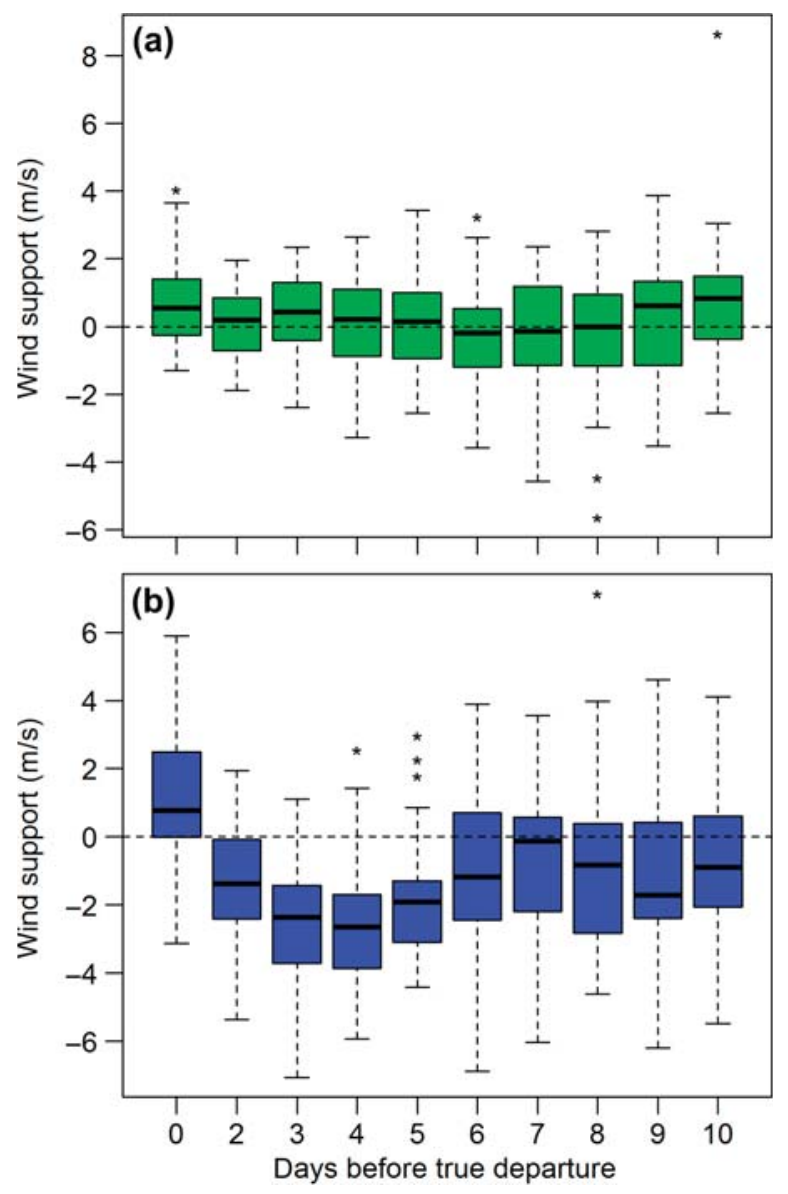

Figure 4. Boxplots of wind support that the geese would experience at different departure times from stopovers during (a) spring migration and (b) autumn migration. It is clearly visible that wind support at observed departure is higher than up to six days before in autumn, but not in spring. The plot for ' 1 day before true departure' has been left out to avoid influence of wind autocorrelation.

favourable winds in autumn and the general availability of favourable winds in spring. Our geese were not restricted to migration during the day, 33\% (spring) and 29\% (autumn) of all flight positions were during night-time.

Similar to wind support at stopover departure, there was no effect of season on wind support of flight positions after observed time of departure (LRT, $\chi^{2}=0.10, \mathrm{DF}=1$, $\mathrm{p}=0.75)$. Different from departure wind support, also flight wind support of all possible shifts of 2-10 days showed no differences between spring and autumn (LRT, $\chi^{2}=1.75$, $\mathrm{DF}=1, \mathrm{p}=0.19)$. However, if selecting only flight wind support with shifts of 2-6 days, a difference between the seasons became visible (LRT, $\chi^{2}=6.35, D F=1, p=0.01$; Fig. 6a). In support of our above findings of higher wind support at true departure than if departing 2-6 days earlier, also flight wind support patterns of autumn showed a significant effect of shifted days (LRT, $\chi^{2}=6.10, \mathrm{DF}=1$, $\mathrm{p}=0.01$; Fig. 6b).

\section{Discussion}

In contrast to the general theory and empirical findings that most avian migrants travel faster during their spring than
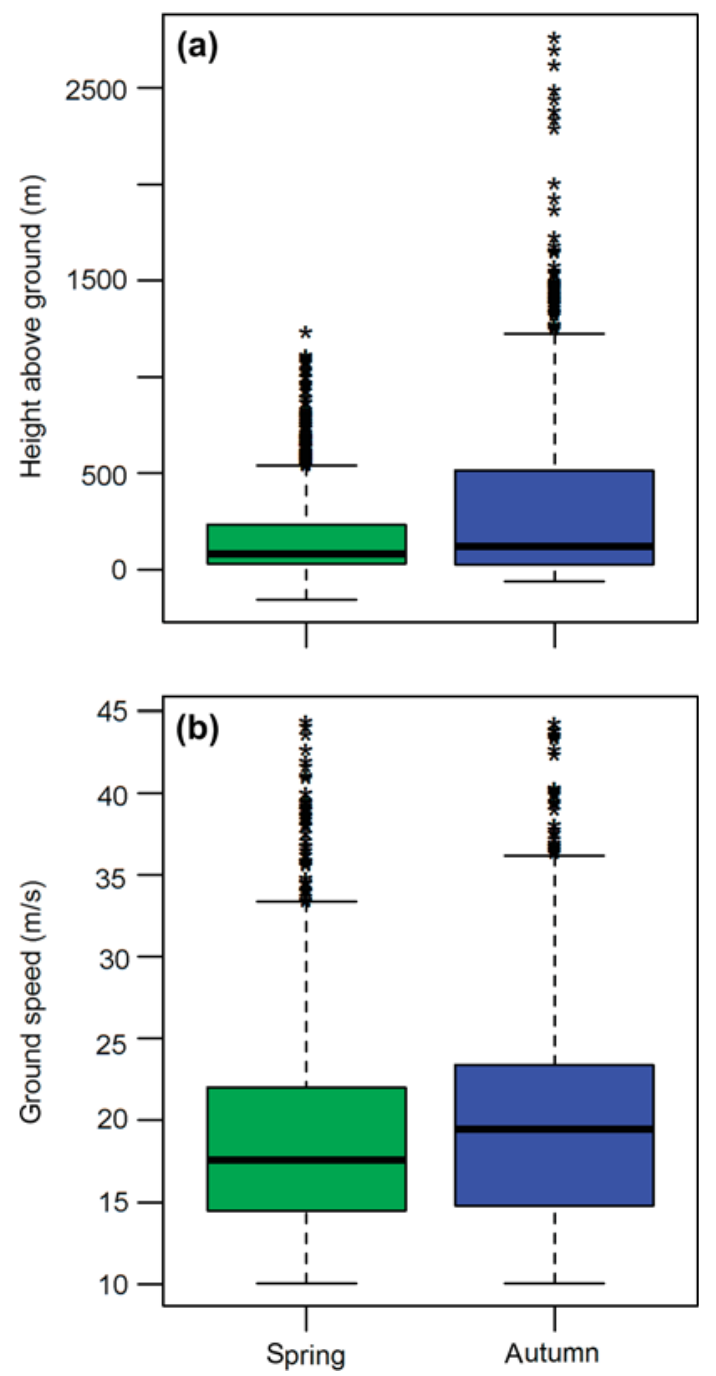

Figure 5. Migration flight properties of the tracked geese during spring (green) and autumn (blue) migration. (a) Boxplots of height above the ground (m) and (b) GPS instantaneous ground speed $\left(\mathrm{m} \mathrm{s}^{-1}\right)$ in the two seasons. Only positions between stopovers with GPS ground speed $>10 \mathrm{~m} \mathrm{~s}^{-1}$ and $<45 \mathrm{~m} \mathrm{~s}^{-1}$ were selected. GLMM test results indicate a significant difference of height above ground, but not ground speed between the seasons.

autumn migration (Kokko 1999, Nilsson et al. 2013), we here provide a case of the opposite. We showed that the migration duration of greater white-fronted geese between central Europe and the Russian Arctic is longer in spring than in autumn and that this might be related to longer stopover durations, but not lower flight speed in spring. Selectivity of geese for supportive wind conditions during stopover departure and migration flight was stronger in autumn. However, due to generally less favourable autumn than spring winds, this only led to compensation and thus similar flight speeds in the two seasons. In combination with previous insights that white-fronted geese are time-delayed during spring migration, follow the green wave of spring growth and put on extra energy stores for early breeding, we compiled an integrated image of how different environmental factors shape the timing of both seasonal migrations of this species. 

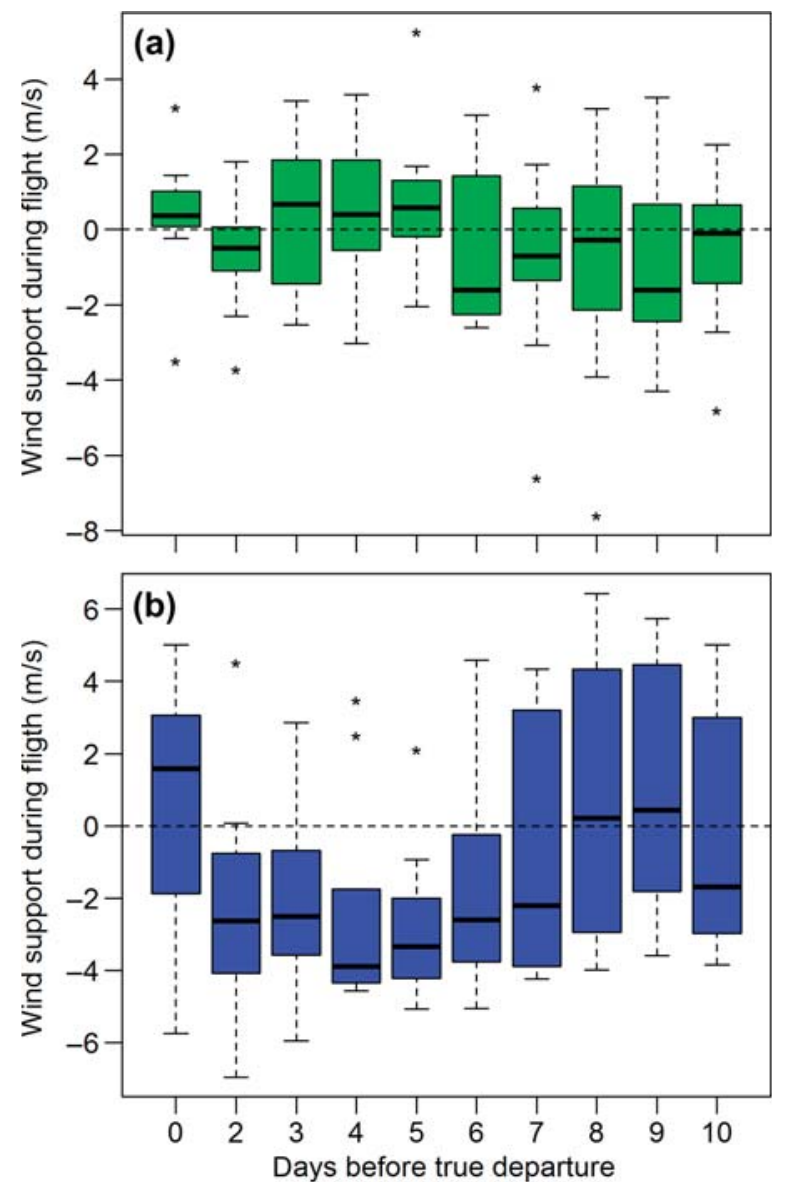

Figure 6. Boxplots of wind support that the geese would experience at recorded flight GPS positions in a $24 \mathrm{~h}$ window after different departures from stopovers during (a) spring migration and (b) autumn migration. It is clearly visible that wind support during flight after observed departure is higher than up to six days before in autumn, but not in spring. The plot for ' 1 day before true departure' has been left out to avoid influence of wind autocorrelation.

The white-fronted goose is not the first species that was found to migrate faster in autumn than in spring (Nilsson et al. 2013); others are the Bewick's swan (Nuijten et al. 2014), northern common eider (Mosbech et al. 2006), white stork (Shamoun-Baranes et al. 2003), black-backed gull (Bustnes et al. 2013), booted eagle (Mellone et al. 2015), Egyptian vulture (Lopez-Lopez et al. 2014), Montagu harrier (Liminana et al. 2012), great snipe (Klaassen et al. 2011) and bar-tailed godwit (Battley et al. 2012). This list of species lacks small passerines, suggesting that body size rather than flight mode (flapping or soaring) might be of importance for their migration strategy. This might be related to the finding that smaller birds cannot opt for capital breeding due to higher relative transportation costs (Klaassen et al. 2001), but could also be caused by the fact that small passerines cannot refuel during migration due to atrophy of their digestive tract (Biebach 1998). However, we cannot rule out that more cases of slower spring than autumn migration will be found once it will be possible to follow small birds with GPS during their migratory flights. Interestingly, some of the above species show faster autumn migration in one population, but vice versa in another population (Liminana et al. 2012, Vansteelant et al. 2015), indicating that environmental factors are perhaps in general more likely the drivers of migration timing strategies.

Three main environmental drivers have been suggested to cause migrants to progress slower during spring migration: 1) high individual costs of early arrival to the breeding grounds (Bety et al. 2004), 2) seasonal differences in food availability and 3) seasonal differences in wind conditions (Shamoun-Baranes et al. 2003). Early arrival especially to northern breeding sites might be unfavourable due to harsh climatic conditions, low food availability and increased predation risk, and has been shown to lead to lower probability of breeding in greater snow geese (Bety et al. 2004). In addition, before spring departure the birds might be limited by decreased food availability in the wintering areas and thus forced to replenish their energy supplies during migration (Shamoun-Baranes et al. 2003), and environmental conditions like successive spring warming and snow and ice melt might force the birds to move slowly towards northern breeding sites (Bauer et al. 2006, Nuijten et al. 2014). On the other hand, just before autumn migration, food availability is often assumed to be high, enabling the birds to start migrating fast and in a good condition. Furthermore, depending on the areas that the migrants have to cross, wind conditions (tail winds and/or thermals) might be more advantageous in autumn allowing for higher migration speed (Shamoun-Baranes et al. 2003).

One of the suggested environmental drivers seems to act strongly on our white-fronted geese: differences in food availability. Their generally long stopovers in Nenetsky Okrug just before their very long, often non-stop flight to their wintering grounds in autumn indicates that food availability in this site was high (as opposed to along the route). Here geese have been observed to feed on highly abundant cloud berries Rubus chamaemorus, which are extremely energy rich and can fuel a fast, non-stop autumn migration (A. Kondratyev pers. comm.). In this way the geese can avoid autumn hunting and pass over areas with lower food abundance. Regarding spring migration, we have previously shown that white-fronted geese follow the stepwise snow melt and green wave of vegetation growth along their route (van Wijk et al. 2012). Furthermore, they are partly capital breeders that need to arrive at their breeding grounds with already accumulated energy stores to achieve successful breeding (Spaans et al. 1999). This capital energy is used for the production of an early clutch and during incubation, when the female hardly ever leaves the nest. Thus, regardless of the food availability in the wintering grounds, our geese chose to avoid costly transportation and to forage on the high quality vegetation along their spring migration route, resulting in the longer stopover times during spring. In support thereof, we have shown that the geese were flying shorter distances after the same duration of stopover in spring than in autumn, indicating that they accumulated extra energy stores only in spring. Additionally, Arctic geese have been shown to delay arrival to the breeding grounds in years of late snow melt, avoiding long waiting times (with low food availability and high predation pressure) for nest sites to become snow free (Black et al. 2014). 
Our results indicate that, as obligate flapping migrants, white-fronted geese made use of tail winds during stopover departure and travel flight, especially in autumn. This finding conforms with the theory that birds with high energy cost of travel and the ability of fuel deposition during migration should be highly selective for supporting winds (Thorup et al. 2006). During autumn, general wind conditions along the birds' travel route were highly adverse (Supplementary material Appendix 1 Fig. A3), and runs of days with supportive winds generally short (Åkesson and Hedenström 2000, Beekman et al. 2002). The long stopover that our birds made before departure from the region of Nenetsky Okrug and the significantly better winds at stopover departure compared to several days before indicates that they dealt with the adverse wind conditions by using a so-called "sit and wait for favourable winds" strategy (Gauthreaux et al. 2005). Most of the geese directly migrated from Nenetsky Okrug to the wintering grounds, which might reflect the fact that periods of favourable winds are usually very short in autumn (Kemp et al. 2010). High within-year similarity of migration timing and tail wind use during autumn supports this notion of a high selectivity for supportive winds that do not occur often. During spring, the prevailing winds were favourable for our birds' northeasterly migration. Geese did not need to wait much and could "go with the flow" (Gauthreaux et al. 2005) once the green wave allowed so. In general, during spring migration, they did not select for supporting winds during stopover departure, but adverse winds were generally rare and variance low.

Importantly, the higher selectivity for favourable winds during autumn migration has only led to equal flight speeds in the two seasons. It does not explain the faster autumn migration. The geese have corrected flight speeds into the right direction (they would be lower for autumn migration if geese would time migration flight randomly), but the magnitude of this change (speed increase by 3-4 $\mathrm{m} \mathrm{s}^{-1}$ during ca five flight days) is certainly less than the increase by (in total ca 41 days) longer stopover duration.

It was shown earlier that greater white-fronted geese that migrate from Ireland to breed on Greenland selected favourable winds during spring migration (Fox et al. 2003). As these birds move in a region of completely different weather system, this finding does not contradict our conclusion; it rather supports the notion that geese can select for supportive winds if beneficial.

One issue that should be discussed when working with GPS tracks and weather-reanalysis data sets is their resolution and reliability. We consider our GPS data set (incl. the instantaneous GPS speed) sufficiently accurate, as their error (up to $15 \mathrm{~m}$ ) is far lower than the grid cell size of the ECMWF wind data set (about $84 \mathrm{~km}$ at the equator). Errors of ECMWF ocean wind speeds have been estimated as $0.8-1.3 \mathrm{~m} \mathrm{~s}^{-1}$ for winds $<16 \mathrm{~m} \mathrm{~s}^{-1}$ (Hoffman et al. 2013), which is lower than the effect on wind support (Fig. 4, 6) due to departure time selectivity. Even if wind data errors are larger over land (Safi et al. 2013), where our geese are mainly moving, we would expect our results to be weakened by lower local wind data accuracy. Thus, our geese' selectivity of departure wind conditions might be even stronger than our findings suggest.
Apart from the differences in timing and wind selectivity, also migration routes of our white-fronted geese varied strongly between the seasons. In autumn, all geese moved along a narrow corridor following the coast lines, whereas they spread out in a wide front of routes during spring migration. This difference in route selectivity suggests differences in requirements, ecological drivers and ecological barriers between the seasons. These were likely similar to factors that determined migration timing; lower general food availability might have forced the geese to spread out in spring to avoid direct intra- and interspecific competition for food. In addition, strong supportive southern winds along the Volga river, southeast of Moscow, (Supplementary material Appendix 1 Fig. A2) and a delayed spring snow melt towards the north (Supplementary material Appendix 1 Fig. A3) may benefit the geese that take the longer southern migration route during spring migration. This is supported by the finding that the geese did not take longer time for larger travelled distances (southern route) in spring (Fig. 3c) suggests that they fly further after similar stopover durations (and thus fuelling times), indicating that food quality or daily food intake is higher along the southern route.

Thus, even if there are no obvious ecological barriers along their spring migration route (like large stretches of ocean that the Greenland population of greater whitefronted geese has to pass, Fox et al. 2003), our geese might experience a set of different limitations depending on the route they have selected. Several individuals might select the longer, southern detour (Åkesson et al. 2012) because of less competition, predation, disturbance and hunting pressure than along the alternative routes. In spring they could not quickly fly over dangerous areas, because they were restricted by delayed onset of spring and needed to collect extra stores for breeding, but could possibly pass around them. In autumn, however, our white-fronted geese could fill their energy stores prior to departure in one region, namely the area of the Nenetsky Okrug, and then quickly move to central Europe, flying day and night (Alerstam 2009) to minimise exposure to dangers on the way. Such behaviour indicates that the birds might have experienced an ecological barrier (Åkesson and Hedenström 2007, Klaassen et al. 2008, Kölzsch et al. 2015), even if this barrier between northern Russia and Poland is likely less driven by the classically considered ecological barrier factors (food availability and wind conditions), but by predation and hunting pressure.

Different from non-stop migrants like light-bellied brent geese Branta bernicla hrota that have developed a mismatch of spring migration and the drastically changing phenology in their breeding grounds (Clausen and Clausen 2013), the greater white-fronted geese of our population seem able, by using many stopovers on different routes in spring, to predict conditions and adjust their timing under a changing environment (Kölzsch et al. 2015). However, most relevant conditions like food availability during spring migration might hamper population growth eventually. Russia is presently experiencing strong changes in the use of agricultural land (Glazov et al. 2013). Many fields stay uncultivated and grass is growing too long for geese to efficiently use it for foraging in spring. In combination with increased hunting 
pressure in spring and wintering grounds this might lead to problems for the population (Bechet et al. 2003). We propose that it is a general phenomenon that animals adopt different decision rules to most efficiently arrange their spring and autumn migrations in time and space. This leads to differences in spring and autumn migration durations. However, as the climate and environments are presently under dramatic change (IPCC 2007), animals will adapt by e.g. shortened spring migration (Eichhorn et al. 2009) and migration patterns might shuffle.

Acknowledgements - We would like to thank the Vogelschutz-Komitee e.V. (VsK Hamburg), Alterra Wageningen-UR and the Dutch Society of Goose catchers for the financial and technical support in catching and tagging the geese in their Dutch wintering grounds. Catching geese in the Russian breeding grounds was performed as a collaboration of the Inst. of Geography-RAS, Alterra WageningenUR, the Inst. for Waterbird and Wetlands Research (IWWR) e.V. and the Max Planck Inst. for Ornithology. We acknowledge funding from the DLR through the ICARUS directive. For help with data download in the wintering grounds we are grateful to Rosanne Beukeboom, Jan Kramer, Harm van de Wal, Thijs de Boer, Frank Joisten, Lothar Henschel, Werner Habicht and several colleagues from SOVON and Staatsbosbeheer. For reading out data from neckband loggers, we are much obliged to a large number of bird watchers that found the tagged geese and reported their positions. We would like to thank Bart Kranstauber and Kamran Safi for discussion about analysis methods.

\section{References}

Åkesson, S. and Hedenström, A. 2000. Wind selectivity of migratory flight departures in birds. - Behav. Ecol. Sociobiol. 47: $140-144$.

Åkesson, S. and Hedenström, A. 2007. How migrants get there: migratory performance and orientation. - Bioscience 57: $123-133$.

Åkesson, S. et al. 2012. Migration routes and strategies in a highly aerial migrant, the common swift Apus apus, revealed by lightlevel geolocators. - PloS ONE 7: e41195.

Alerstam, T. 2009. Flight by night or day? Optimal daily timing of bird migration. - J. Theor. Biol. 258: 530-536.

Alerstam, T. et al. 2007. Flight speeds among bird species: allometric and phylogenetic effects. - PloS Biol. 5: 1656-1662.

Barry, T. 1967. Geese of the Anderson River Delta, Northwest Territories. - Dept of Zoology, Univ. of Alberta.

Battley, P. F. et al. 2012. Contrasting extreme long-distance migration patterns in bar-tailed godwits Limosa lapponica. - J. Avian Biol. 43: 21-32.

Bauer, S. et al. 2006. Intake rates, stochasticity, or onset of spring - what aspects of food availability affect spring migration patterns in pink-footed geese Anser brachyrhynchus? - Ardea 94: 555-566.

Bechet, A. et al. 2003. Spring hunting changes the regional movements of migrating greater snow geese. - J. Appl. Ecol. 40: 553-564.

Beekman, J. H. et al. 2002. Skipping swans: fuelling rates and wind conditions determine differential use of migratory stopover sites of Bewick's swans Cygnus bewickii. - Ardea 90: $437-460$.

Bety, J. et al. 2004. Individual variation in timing of migration: causes and reproductive consequences in greater snow geese (Anser caerulescens atlanticus). - Behav. Ecol. Sociobiol. 57: $1-8$.
Biebach, H. 1998. Phenotypic organ flexibility in garden warblers Sylvia borin during long-distance migration. - J. Avian Biol. 29: 529-535.

Black, J. M. et al. 2014. The barnacle goose. - T and AD Poyser. Bustnes, J. O. et al. 2013. Rapid long-distance migration in Norwegian lesser black-backed gulls Larus fuscus fuscus along their eastern flyway. - Ibis 155: 402-406.

Clausen, K. K. and Clausen, P. 2013. Earlier Arctic springs cause phenological mismatch in long-distance migrants. - Oecologia 173: 1101-1112.

Clausen, K. K. and Madsen, J. 2014. Effects of neckbands on body condition of migratory geese. - J. Ornithol. 155: 951-958.

De Boer, R. et al. 2014. A comparison of spring migration between three populations of barnacle geese Branta leucopsis using GPS satellite transmitters. - Limosa 87: 99-106.

Demers, F. et al. 2003. Effects of collar-attached transmitters on behaviour, pair bond and breeding success of snow geese Anser caerulescens atlanticus. - Wildl. Biol. 9: 161-170.

Dodge, S. et al. 2013. The environmental-data automated track annotation (Env-DATA) system: linking animal tracks with environmental data. - Movement Ecol. 1: 3.

Drent, R. H. and Daan, S. 1980. The prudent parent - energetic adjustments in avian breeding. - Ardea 68: 225-252.

Drent, R. J. et al. 2006. Travelling to breed. - J. Ornithol. 147: $122-134$.

Drent, R. H. et al. 2007. Migratory connectivity in Arctic geese: spring stopovers are the weak links in meeting targets for breeding. - J. Ornithol. 148: S501-S514.

Eichhorn, G. et al. 2009. Skipping the Baltic: the emergence of a dichotomy of alternative spring migration strategies in Russian barnacle geese. - J. Anim. Ecol. 78: 63-72.

Ely, C. R. 1976. Breeding biology of the white-frotned goose (Anser albifrons frontalis) on the Yukon-Kuskokwim Delta, Alaska. - MS thesis, Univ. of California.

Ely, C. R. 1990. Effects of neck bands on the behavior of wintering greater white-fronted geese. - J. Field Ornithol. 61: 249-253.

Fox, A. D. et al. 1995. Mutual benefits of associations between breeding and non-breeding white-fronted geese Anser albifrons. - Ibis 137: 151-156.

Fox, A. D. et al. 2003. Spring migration routes and timing of Greenland white-fronted geese - results from satellite telemetry. - Oikos 103: 415-425.

Gauthreaux, S. A., Jr. et al. 2005. The temporal and spatial structure of the atmosphere and its influence on bird migration strategies. - In: Greenberg, R. and Marra, P. P. (eds), Birds of two worlds: the ecology and evolution of migration. The John Hopkins Univ. Press.

Glahder, C. M. et al. 1998. Effects of fitting dummy satellite transmitters to Greenland white-fronted geese Anser albifrons flavirostris. - Wildfowl 48: 88-97.

Glazov, P. et al. 2013. Geese spring staging areas in central European part of Russia: conditions and conservation problems. - Int. Union of Game Biol. Congr., p. 176.

Green, M. et al. 2002. Dark-bellied Brent geese Branta bernicla bernicla, as recorded by satellite telemetry, do not minimize flight distance during spring migration.- Ibis 144: 106-121.

Hedenström, A. and Alerstam, T. 1997. Optimum fuel loads in migratory birds: distinguishing between time and energy minimization. - J. Theor. Biol. 189: 227-234.

Hoffman, R. N. et al. 2013. Error estimates for ocean surface winds: applying desroziers diagnostics to the cross-calibrated, multiplatform analysis of wind speed. - J. Atmos. Oceanic Technol. 30: 2596-2603.

IPCC 2007. Climate change 2007: synthesis report. Contrib. Working Grps I, II and III to the 4th Assess. Rep. Intergovernmental Panel Climate Change. - In: Pachauri, R. K. and Reisinger, A. (eds), IPCC, p. 104 pp. 
Kemp, M. U. et al. 2010. Can wind help explain seasonal differences in avian migration speed? - J. Avian Biol. 41: 672-677.

Klaassen, M. et al. 2001. Ornithology: arctic waders are not capital breeders. - Nature 413: 794.

Klaassen, R. H. G. et al. 2008. Flexibility in daily travel routines causes regional variation in bird migration speed. - Behav. Ecol. Sociobiol. 62: 1427-1432.

Klaassen, R. H. G. et al. 2011. Great flights by great snipes: long and fast non-stop migration over benign habitats. - Biol. Lett. 7: 833-835.

Kokko, H. 1999. Competition for early arrival in migratory birds. - J. Anim. Ecol. 68: 940-950.

Kölzsch, A. et al. 2015. Forecasting spring from afar? Timing of migration and predictability of phenology along different migration routes of an avian herbivore. - J. Anim. Ecol. 84: $272-283$.

Kölzsch, A. et al. 2016. Data from: Towards a new understanding of migration timing: slower spring than autumn migration in geese reflects different decision rules for stopover use and departure. Movebank Data Repository. DOI: 10.5441/001/ $1.31 \mathrm{c} 2 \mathrm{v} 92 \mathrm{f}$

Liechti, F. 2006. Birds: blowin' by the wind? - J. Ornithol. 147: 202-211.

Liminana, R. et al. 2012. Migration and wintering areas of adult Montagu's harriers (Circus pygargus) breeding in Spain. - J. Ornithol. 153: 85-93.

Liminana, R. et al. 2013. Is there a different response to winds during migration between soaring and flapping raptors? An example with the Montagu's harrier and the lesser kestrel. - Behav. Ecol. Sociobiol. 67: 823-835.

Lopez-Lopez, P. et al. 2014. Individual repeatability in timing and spatial flexibility of migration routes of trans-Saharan migratory raptors. - Curr. Zool. 60: 642-652.

Mellone, U. et al. 2015. Seasonal differences in migration patterns of a soaring bird in relation to environmental conditions: a multi-scale approach. - Behav. Ecol. Sociobiol. 69: $75-82$.

Menu, S. et al. 2000. Effects of neck bands on survival of greater snow geese. - J. Wildl. Manage. 64: 544-552.

Moore, F. R. et al. 2005. Stopover ecology of intercontinental migrants: en route problems and consequences for reproductive performance.

Supplementary material (available online as Appendix oik-03121 at <www.oikosjournal.org/appendix/oik-03121 >). Appendix 1.
Mosbech, A. et al. 2006. Year-round movements of northern common eiders Somateria mollissima borealis breeding in Arctic Canada and west Greenland followed by satellite telemetry. - Ardea 94: 651-665.

Nilsson, C. et al. 2013. Differences in speed and duration of bird migration between spring and autumn. - Am. Nat. 181: 837-845.

Nolet, B. A. 2006. Speed of spring migration of tundra swans Cygnus columbianusin accordance with income or capital breeding strategy? - Ardea 94: 579-591.

Nuijten, R. J. M. et al. 2014. The exception to the rule: retreating ice front makes Bewick's swans Cygnus columbianus bewickii migrate slower in spring than in autumn. - J. Avian Biol. 45: 113-122.

Pennycuick, C. J. et al. 2013. Air speeds of migrating birds observed by ornithodolite and compared with predictions from flight theory. - J. R. Soc. Interface 10: 20130419.

Prop, J. et al. 2003. Travel schedules to the high arctic: barnacle geese tradeoff the timing of migration with accumulation of fat deposits. - Oikos 103: 403-414.

Safi, K. et al. 2013. Flying with the wind: scale dependency of speed and direction measurements in modelling wind support in avian flight. - Movement Ecol. 1: 4-4.

Shamoun-Baranes, J. et al. 2003. The effect of wind, season and latitude on the migration speed of white storks Ciconia ciconia, along the eastern route. - J. Avian Biol. 34: 97-104.

Spaans, B. et al. 1999. Cost of incubation in a greater white-fronted goose. - Waterbirds 22: 151-155.

Thorup, K. et al. 2006. Traveling or stopping of migrating birds in relation to wind: an illustration for the osprey. - Behav. Ecol. 17: 497-502.

Tombre, I. M. et al. 2008. The onset of spring and timing of migration in two arctic nesting goose populations: the pinkfooted goose Anser bachyrhynchus and the barnacle goose Branta leucopsis. - J. Avian Biol. 39: 691-703.

van der Graaf, S. et al. 2006. Surfing on a green wave - how plant growth drives spring migration in the barnacle goose Branta leucopsis. - Ardea 94: 567-577.

van Wijk, R. E. et al. 2012. Individually tracked geese follow peaks of temperature acceleration during spring migration. - Oikos 121: 655-664.

Vansteelant, W. M. G. et al. 2015. Regional and seasonal flight speeds of soaring migrants and the role of weather conditions at hourly and daily scales. - J. Avian Biol. 46: 25-39. 